\title{
Conhecimentos e atitudes das mulheres em relação ao exame preventivo do câncer do colo uterino
}

Florencia Vicente Chiconela ${ }^{1}$, José Braz Chidassicua ${ }^{2}$

\author{
${ }^{1}$ Enfermeira, Instituto Superior de Ciências \\ de Saúde. Maputo, Moçambique. E-mail: \\ chiconelaflo@gmail.com. \\ ${ }^{2}$ Historiador, Mestre em Saúde Pública. \\ Instituto Nacional de Saúde. Maputo, \\ Moçambique. E-mail: \\ chidassicua@gmail.com.
}

Recebido: 16/05/2016.

Aceito: 07/02/2017.

Publicado: 06/09/2017.

Como citar esse artigo:

Chiconela FV, Chidassicua JB.

Conhecimentos e atitudes das mulheres em relação ao exame preventivo do câncer do colo uterino. Rev. Eletr. Enf. [Internet]. 2017 [acesso em:______ ];19:a23.

Disponível em:

http://dx.doi.org/10.5216/ree.v19.41334.

\section{RESUMO}

Este estudo teve por objetivo avaliar os conhecimentos e atitudes das mulheres em relação a importância do exame preventivo do câncer do colo uterino. Estudo descritivo e exploratório de abordagem qualitativa, realizado com 14 mulheres atendidas em um serviço de saúde de Moçambique. A coleta de dados foi por meio do roteiro de entrevista semiestruturada, entre os meses de fevereiro a março de 2015. Os resultados foram analisados pela técnica de análise de conteúdo. A maior parte das mulheres embora tenha ouvido falar do câncer do colo uterino (CCU) na televisão e nas palestras dos hospitais, tem pouco conhecimento em relação à prevenção, desconhece a importância do exame preventivo e realiza o exame devido a queixas ginecológicas. $O$ conhecimento das mulheres é incipiente e aquém do esperado sobre a temática da importância do exame preventivo.

Descritores: Neoplasias do Colo do Útero; Prevenção Primária; Atenção Primária à Saúde; Cuidados de Enfermagem.

\section{INTRODUÇÃO}

O câncer do colo uterino (CCU) é uma doença crônico-degenerativa, considerada um problema de saúde pública, tendo em vista sua alta incidência, prevalência, morbidade, mortalidade e demanda de cuidados para os familiares e profissionais da saúde ${ }^{(1)}$.

Mais de $85 \%$ da carga global e $88 \%$ da mortalidade global ocorrem nos países em desenvolvimento devido ao $\mathrm{CCU}$, onde mais de $95 \%$ das mulheres nunca foram examinadas quanto à doença ${ }^{(2-3)}$. A incidência do CCU é consideravelmente mais alta em países em desenvolvimento, especialmente em países subdesenvolvidos, onde ocupa o primeiro lugar na classificação de todos os cânceres femininos, enquanto que nos países desenvolvidos, ocupa apenas o sexto ${ }^{(4-5)}$. 
Em Moçambique, estimativas de 2012 apontam que são diagnosticados anualmente 5.622 novos casos e ocorrem anualmente 4.061 mortes por CCU no país, posicionado como a primeira causa do câncer feminino e de mortes entre mulheres com idade de 15 a 44 anos $^{(6)}$.

O programa de prevenção do CCU em Moçambique evidenciou que a implementação de 2010 a 2013 foram rastreadas 93.500 mulheres para câncer, sendo que $8.650(9,2 \%)$ eram mulheres com visualização com ácido acético (VIA) positiva a lesões pré-cancerosas, 14,8\% eram mulheres com VIA positiva e também HIV positiva, 6.320 (73\%) mulheres com lesões pré-cancerosas eram tratadas com crioterapia e 1.140 (13\%) mulheres com VIA positiva eram referidas a lesões maior que $75 \%$ ou por suspeita de $\mathrm{CCU}^{(7)}$.

Pela atuação em Consulta de Saúde Reprodutiva no Centro de Saúde $1^{\circ}$ de Maio, percebeu-se que algumas mulheres recusavam a realização do exame preventivo do CCU. Assim, foi necessário reconhecer o universo simbólico que o CCU e o exame tem para as mulheres. Tratando-se de um tema não muito explorado em Moçambique e pela sua relevância social, estudar esse assunto se constitui um desafio a sua compreensão e uma contribuição social.

Os resultados deste estudo poderão servir de instrumento para informar as mulheres, família e a comunidade em geral sobre a importância do exame, esclarecimento quanto aos fatores de risco do CCU assim como incentivar para a sua realização.

O presente estudo teve como objetivo descrever os conhecimentos e atitudes das mulheres em relação a importância do exame preventivo do câncer do colo uterino em um serviço de saúde.

\section{METODOLOGIA}

Estudo descritivo-exploratório, de abordagem qualitativa, mediante o qual buscou conhecer em profundidade o universo de significados e atitudes das mulheres em relação a importância do exame preventivo do CCU. A coleta de dados foi realizada durante os meses de fevereiro a março de 2015 na Consulta de Saúde Reprodutiva do Centro de Saúde $1^{\circ}$ de Maio. Trata-se de uma unidade sanitária de nível primário, localizada no bairro de Maxaquene " $C$ " na cidade de Maputo, Moçambique. Ela serve de referência para os bairros de Maxaquene " $B$ ", "C" e " $D$ ", correspondente a uma população de 72.343 habitantes.

Os sujeitos do presente estudo foram 14 mulheres atendidas na Consulta de Saúde Reprodutiva, que realizavam o exame pela primeira vez e outras que faziam o controle após a crioterapia. Os critérios de inclusão foram: ter idade de 30 a 49 anos no período em estudo e ter iniciado atividade sexual. Os critérios de exclusão foram: mulheres que não compareceram no período em estudo. 0 número de mulheres que participaram do estudo não foi previamente estabelecido, considerando-se que a inclusão ocorreu de forma progressiva, sendo interrompida pelo critério de saturação.

A coleta de dados iniciou após as mulheres terem sido informadas da importância e objetivo da pesquisa mediante a assinatura do Termo de Consentimento Livre e Esclarecido (TCLE). Utilizou-se a entrevista semiestruturada como técnica para captação dos dados e as entrevistas foram gravadas e transcritas na íntegra após a anuência das mulheres usando um aparelho MP4 como instrumento. Um roteiro 
de entrevista foi elaborado com a seguinte questão norteadora: Quais são os conhecimentos e atitudes das mulheres em relação ao exame preventivo do câncer do colo uterino? O referido instrumento contemplou dados sociodemográficos para mulheres em que as participantes tiveram a oportunidade de discorrer sobre o tema, abordando aspectos como importância do exame preventivo do CCU.

Para análise de dados utilizou-se a técnica de análise de conteúdo proposta por Bardin. Para fins de compreensão e preservação do sigilo da identidade das mulheres foram identificadas pelas letras "EN" acrescidas pelo número sequencial das entrevistas.

O projeto de pesquisa foi aprovado pelo Comité de Ética Científica do Instituto Superior de Ciências de Saúde (ISCISA) sob no do protocolo 21/14. Toda informação obtida durante este estudo foi manuseada de modo confidencial pela pesquisadora responsável e armazenada em local seguro com acesso apenas da pesquisadora responsável pelo estudo. Os princípios da Declaração de Helsinque que estabelece critérios para as pesquisas envolvendo os seres humanos foram respeitados.

\section{RESULTADOS E DISCUSSÃO}

Em relação aos dados sociodemográficos referentes às mulheres entrevistadas evidenciou-se que das 14 entrevistadas, a maior parte se encontrava na faixa etária entre 30 a 49 anos, sendo a idade média de 38 anos. Eram na maioria, mulheres casadas ou viviam maritalmente, com nível primário de escolaridade. E que tiveram a primeira relação sexual antes de 18 anos de idade.

A incidência desse tipo de câncer é evidenciada em mulheres jovens, a partir dos 20-29 anos, estando o maior risco na faixa etária de $45-49$ anos $^{(8)}$.

Quanto ao estado civil, o comportamento sexual das mulheres casadas e com união estável está associada à infecção pelo $\mathrm{HPV}^{(9)}$. No entanto, mulheres solteiras e sem parceiros fixos, mesmo se expondo a um maior número de parceiros sexuais, apresentaram baixa relação com a infecção pelo vírus, pelo fato de utilizarem preservativos, o que não ocorre com mulheres casadas e em uniões consensuais, devido a uma vida sexual estável, utilizando assim anticoncepcionais com a finalidade de controle de natalidade. Além disso a maior parte das mulheres tinha nível primário de escolaridade. O exame de prevenção é menos valorizado e realizado em mulheres com menor grau de escolaridade ${ }^{(10)}$.

Em relação a idade da 1a relação sexual, estudo evidencia que as mulheres que tiveram o primeiro coito entre 10 a 19 anos podem desenvolver a neoplasia intracervical três vezes mais do que as mulheres que tiveram a primeira relação sexual entre 20 a $30 \operatorname{anos}^{(11)}$.

\section{Conhecimento e atitude das mulheres em relação ao exame preventivo do CCU}

A percepção das mulheres em relação ao CCU foi divergente. Algumas entrevistadas mencionam o CCU como uma doença que se desenvolve no colo uterino. Outras como sendo uma ferida que aparece no colo uterino ou uma infecção do útero. 
Eish, cancro do útero é uma doença que sai feridas no colo do útero desenvolvem as vezes sai sangue, eish, não sei feridas ei. ENO5

Cancro do colo do útero direi que é uma doença obtida ou adquirida do próprio útero nem, que ele é causado por mudanças de abuso sexual sem preservativo com diferentes homens com cada qual tem sua doença. ENO9

O CCU é uma doença evitável que evolui lentamente a partir de lesões precursoras (lesões intraepiteliais escamosas de alto grau e adenocarcinoma insitu), que podem ser diagnosticadas precocemente e tratadas adequadamente, impedindo a progressão para o câncer ${ }^{(12)}$. Resultados do estudo apontam que a maior parte das mulheres entrevistadas (9) desconhecem a definição do CCU. Estudo semelhante constatou que grande parte das mulheres não têm conhecimento sobre o CCU, o exame e sua importância ${ }^{(13)}$.

Questionadas as mulheres em relação a fonte de informação sobre o CCU, a maior parte (8) referiu ter ouvido falar na televisão e nas palestras dos hospitais. Algumas mulheres mencionaram ter obtido a informação por meio de conversas entre amigas, escola e redes sociais.

Já ouvi falar do cancro do colo do útero em várias palestras nos hospitais, livros (...) ENO2 Ei ouvi em vários sítios, televisão, conversas entre amigas, sim! ENO7

As enfermeiras destacam como fator contribuinte no estabelecimento do diálogo com as mulheres, o fato de serem profissionais de enfermagem, ou seja, com preparo para o desenvolvimento de práticas educativas, podendo haver influência do gênero feminino(14).

No intuito de incentivar a mulher para os exames preventivos, a comunicação adotada como estratégia de abordagem nas campanhas deve cuidar-se para não transmitir mensagens que reforçassem valores historicamente construídos sobre a sexualidade feminina, como os que as fragilizam e as responsabilizam por suas práticas sexuais e de cuidados com seu corpo ${ }^{(15)}$. Além disso, é importante salientar que não basta apenas garantir o acesso ao exame preventivo nos serviços de saúde, tampouco emitir informações acerca do mesmo, visto que é necessário garantir que a mulher tenha acesso a informações corretas, para que procurem o exame de prevenção do câncer sem agravo.

Em relação a principal causa do CCU, embora a maior parte das mulheres entrevistadas (8) não soube mencionar a causa do CCU, algumas mulheres souberam mencionar a causa, mas não souberam dizer o nome do vírus e outras (2) demonstraram ter conhecimento ao referirem como principal causa, o vírus do papiloma humano.

O cancro é causado por um vírus, (...). ENO7

A principal causa do cancro do colo do útero é o vírus do papiloma humano (HPV). ENO11

Os resultados apontam que a maior parte das mulheres não está informada da principal causa do CCU. Existem evidências epidemiológicas consistentes de que o vírus do papiloma humano (HPV) é causa necessária para a ocorrência do câncer cervical. A história natural demonstra claramente que a infecção pelo HPV precede o desenvolvimento do câncer cervical em vários anos, e confirma que a transmissão sexual é o 
modo predominante de aquisição do vírus. Estima-se que $70 \%$ de todos os cânceres cervicais do mundo são provocados pelos HPV 16 e $18^{(16)}$.

A percepção em relação as vias de transmissão do vírus do papiloma humano foi diversificada. Embora mais da metade das mulheres (10) referiu contato sexual como via de transmissão, algumas não souberam responder e outras demonstraram ter conhecimento em relação as vias de transmissão, tais como ilustram os relatos a seguir.

Mas o vírus é transmitido através do sexo ei, sexo sem protecção nem (...). ENO7

A principal via de transmissão é a sexual e as outras são via de parto, beijo, partilhas de roupas contaminadas (...). ENO2

Grande parte das mulheres tem conhecimento que a principal via de transmissão do vírus do papiloma humano é por contato sexual. Estudo semelhante afirma que o HPV é transmitido principalmente por via sexual através do contato direto com a pele ou mucosa infectada ${ }^{(16)}$. Aproximadamente $40 \%$ das mulheres sexualmente ativas são infectadas pelo HPV que é transmitido predominantemente pelo contato genital com a pessoa infectada, incluindo sexo oral, por via sanguínea, de mãe para filho no momento do parto (maternofetal) ou por meio de instrumentos ginecológicos não esterilizados, assim como por trauma, objetos contaminados (toalhas, roupas íntimas, banheiros, saunas) ${ }^{(17-18)}$.

Quando questionadas as mulheres em relação aos fatores de risco para CCU, metade (7) mencionou de forma correta a multiplicidade de parceiros e a má alimentação como fatores de risco para CCU.

Naquilo ali aparece através por ter muitos parceiros, ter 1 as vezes 3 parceiros se não evitar porque isso prejudica a minha vida pessoalmente (...). EN014

Pra quem tem muitos filhos, quem começou a fazer relação sexual cedo, quem tem muitos parceiros e alguém com HIV, $\operatorname{sim!(...).~EN06~}$

Diante dos resultados observou-se que a metade descreve a multiplicidade de parceiros e a má alimentação como principais fatores de risco. Estudos afirmam que os principais fatores de risco para o CCU são atividade sexual precoce, baixo nível sociocultural, multiparidade, multiplicidade de parceiros, tabagismo, uso de pílulas anticoncepcionais por longos períodos e a infecção pelo vírus HPV que está presente em mais de $90 \%$ dos casos de $\mathrm{CCU}^{(19-20)}$. É de grande relevância o resultado de que as mulheres associaram apenas dois fatores de risco ao $\mathrm{CCU}$, pois, para aderirem as estratégias preventivas é necessário que as mulheres conheçam os fatores de risco para o CCU.

Considerando que a aceitação e a procura para realizar o exame preventivo se devem, especialmente, à compreensão por parte da mulher da importância deste ato para a manutenção da sua saúde, torna-se importante apreender a influência do comportamento social diante da prevenção do $\mathrm{CCU}^{(21)}$. Entretanto, mais da metade das mulheres entrevistadas (9) mostrou-se desinformada quanto a importância e a finalidade do exame preventivo do CCU como aparece nas falas a seguir:

Considero muito importante porque assim pode prevenir-se nem, é fácil de prevenir se calhar, detectar a doença na fase inicial é fácil tratar e enfim (...) se descobre já muito tarde já quando a doença manifesta por si só ai já poderá ser tarde. 
ENO2

Considero sim, porque estou a sentir as dores e não sei qual é a doença que tenho! ENO14

Considerando também que em sua maioria, as mulheres desconhecem a finalidade do exame preventivo do CCU é possível inferir que apesar da doença apresentar altos potenciais de prevenção por meio do rastreamento oportunístico, ainda existem mulheres que desenvolvem e morrem por este tipo de cancro, pelo fato de desconhecerem a finalidade do exame citopatológico do $\mathrm{CCU}^{(22)}$.

Quando questionadas em relação ao motivo da realização do exame do CCU, oito das mulheres entrevistadas mencionaram que realizam o exame por diversas queixas ginecológicas. Uma mulher entrevistada mencionou a hereditariedade como motivo da realização do exame. Outra mulher alegou o desejo de ter um filho saudável na idade de 30 anos como motivo de realizar o exame do CCU.

Entre outros depoimentos destacamos dois deles pela peculiaridade dos motivos que levaram a busca pelo exame:

Por causa da dor que tô a sentir, às vezes a minha barriga fica parece que tô grávida de seis meses, às vezes eu sinto dor, às vezes um pouco de corrimento, às vezes ao andar o útero queixa-se. ENO10

Vim fazer porque estou com uns sintomas esquisitos do útero nem, é por isso vim, prefiro saber o quê que é, dores, as vezes tiro corrimentos estranhos para mim é. ENO9

Essas mulheres não distinguem apropriadamente a coleta de material para o exame preventivo do exame ginecológico, associando a realização do mesmo de forma curativa, advinda muitas vezes de queixas ginecológicas com sintomatologias específicas, ou até mesmo à falta de sintomas. Essas falas são semelhantes às encontradas em outro estudo ${ }^{(8)}$.

Com relação a idade para se realizar o exame preventivo do CCU, mais da metade das mulheres entrevistadas demonstrou não ter conhecimento em relação a idade recomendada para se efetuar o exame do CCU. Somente seis mulheres demonstraram ter conhecimento ao referir a idade recomendada para realizar o exame do CCU. Para elas, a idade recomendada é a partir dos 30 anos.

(...) que a partir do momento é que a pessoa comece a ter relação sexual, eu acho que pode fazer o rastreio. ENO2

(...) qualquer idade, a pessoa basta mesmo sentir dores. ENO5

Os resultados evidenciam que as mulheres desconhecem a idade para a realização do exame preventivo do CCU. O Ministério da Saúde no Brasil preconiza como grupo prioritário para realização do exame de rastreamento do CCU (Papanicolau) mulheres entre 25 e 64 anos. Entretanto, a incidência desse tipo de câncer no Brasil é evidenciada a partir dos 20-29 anos, estando o maior risco na faixa etária de 45-49 $\operatorname{anos}^{(8)}$.

Diante das medidas preventivas, as mulheres entrevistadas mencionaram o uso de preservativo nas relações sexuais e o exame como umas das formas de prevenção do CCU.

Através do preservativo acho, já nós que já somos casados não sei, o problema é esse mesmo, já somos casados a viver com nossos maridos, não é fácil ahahaha (risos)! EN06 
Primeiro é fazer o rastreio e também reduzir o número de parceiros, no caso, da pessoa ser assim muito ativa e (...) ser muito higiênica sobretudo. EN02

As entrevistadas revelam pouco conhecimento em relação a prevenção do CCU. Estudo semelhante sinaliza que a desinformação, o conhecimento errôneo ou insuficiente constituem barreiras à realização de medidas preventivas para o $\mathrm{CCU}$, como a realização do exame preventivo ${ }^{(8-23)}$.

As lesões, quando presentes, são contagiosas e em alguns casos, o uso do preservativo, por si só, não assegura proteção. No entanto, embora essas lesões possam ser assintomáticas e transitórias, sua evolução está intimamente relacionada com a persistência do DNA viral, algumas mulheres desenvolvem infecções persistentes e que podem resultar em lesões precursoras do $\mathrm{CCU}^{(16-19)}$.

As mulheres entrevistadas não aderiram a consulta ginecológica nos últimos 12 meses por vários motivos socioeconômicos. Como era de se esperar, todas elas referiram que procuravam a consulta caso sentissem algum mal-estar. Eis o extrato de fala de algumas entrevistadas:

Não, não fiz nenhuma consulta ginecológica, porque o trabalho não mim deixa com tempo, dinheiro pra chapa não tenho para vir sempre ao hospital para essa consulta sem eu sentir nada. EN09

Não fiz consulta ginecológica porque meu trabalho é duro e não tenho tempo para perder com essas consultas e não só dependo desse dinheiro para cuidar dos meus filhos já que sou viúva, não tenho ajuda. EN014

O baixo nível socioeconômico das mulheres entrevistadas contribui como barreira à realização de medidas preventivas para o $\mathrm{CCU}$, pois, à medida que diminui o nível socioeconômico, aumenta significativamente a prevalência de mulheres sem cobertura pelo exame preventivo ${ }^{(23-24)}$.

\section{CONCLUSÃO}

A partir dos resultados desta pesquisa, infere-se que, apesar da existência do exame do CCU, as mulheres procuram o exame quando há algum incômodo, retardando o diagnóstico precoce da doença.

A maior parte das mulheres, embora já tenha ouvido falar do CCU, e tenha conhecimento sobre a principal via de transmissão do $\mathrm{CCU}$, tem falta de conhecimento em relação a importância do exame preventivo e seus fatores de risco. Este fato contribuiu para que elas somente realizem o exame quando apresentam sinais e sintomas ginecológicos.

Neste contexto, torna-se necessário reforçar e fortalecer programas voltados para a educação, divulgação e orientação sobre a doença e as respetivas medidas preventivas, de modo que haja uma redução dos indicadores de morbimortalidade por este tipo de câncer, impactando de maneira positiva na qualidade de vida das mulheres. Mais pesquisas sobre CCU são necessárias, tanto com mulheres que realizaram o exame preventivo assim como aquelas que mesmo tendo informação ignoram o exame do CCU.

\section{REFERÊNCIAS}

1. Herr GE, Kolankiewicz ACB, Berlezi EM, Gomes JS, Magnago TSBS, Rosanelli CP et al. Avaliação de conhecimentos acerca da doença oncológica e práticas de cuidado com a saúde. Revista Brasileira de Cancerologia [Internet]. 2013 
[acesso em: 06 set. 2017];59(1):33-41. Disponível em: http://www1.inca.gov.br/rbc/n_59/v01/pdf/06-avaliacao-deconhecimentos-acerca-da-doenca-oncologica-e-praticas-de-cuidado-com-a-saude.pdf.

2. Jemal A, Bray F, Center MM, Ferlay J, Ward E, Forman D. Global cancer statistics. CA Cancer J Clin [Internet]. 2011 [acesso em: 06 set. 2017];61(2):69-90. Disponível em: http://dx.doi.org/10.3322/caac.20107.

3. Moving cancer up the global health agenda. Lancet [Internet]. 2010 [acesso em: 06 set. 2017];375(9731):2051. Disponível em: http://dx.doi.org/10.1016/S0140-6736(10)60942-7.

4. Campbell CMP, Curado MP, Harlow SD, Soliman AS. Variation of cervical cancer incidence in Latin America and the Caribbean. Rev Panam Salud Publica [Internet]. 2012 [acesso em: 06 set. 2017];31(6):492-8. Disponível em: http://dx.doi.org/10.1590/S1020-49892012000600007.

5. Fonseca AJ, Ferreira LP, Dalla-Benetta AC, Roldan CN, Ferreira MLS. Epidemiologia e impacto econômico do câncer de colo de útero no Estado de Roraima: a perspectiva do SUS. Rev Bras Ginecol e Obs [Internet]. 2010 [acesso em: 06 set. 2017];32(8):386-92. Disponível em: http://dx.doi.org/10.1590/S0100-72032010000800005.

6. Bruni L, Barrionuevo-Rosas L, Albero G, Aldea M, Serrano B, Valencia S et tal. ICO Information Centre on HPV and Cancer (HPV Information Centre): Human Papillomavirus and Related Diseases in Mozambique. Summary Report 2016. 2016:2-26.

7. Matos C, Chongo L, Samucidine M, Vaz ML. Scaling-up cervical cancer prevention program in Mozambique. In: $1^{\circ}$ FIGO Africa Regional Congress of Gynecology and Obstetrics, 2013, Addis Ababa, Etiopia [Internet]. 2013 [acesso em: 06 set. 2017]. Disponível em: http://www.mchip.net/sites/default/files/mchipfiles/CECAP_Addis.pdf.

8. Rico AM, Iriart JAB. "Tem mulher, tem preventivo: sentidos das práticas preventivas do câncer do colo do útero entre mulheres de Salvador, Bahia, Brasil. Cad Saude Publica [Internet]. 2013 [acesso em: 06 set. 2017];29(9):1763-73. Disponível em: http://dx.doi.org/10.1590/0102-311X00146512.

9. Nonnenmacher B, Breitenbach V, Villa LL, Prolla JC, Bozzetti MC. Identificação do papilomavírus humano por biologia molecular em mulheres assintomáticas. Rev Saude Publica [Internet]. 2002 [acesso em: 06 set.

2017];36(1):95-100. Disponível em: http://dx.doi.org/10.1590/S0034-89102002000100015.

10. Oliveira AEC, Deininger LSC, Lucena KDT. O olhar das mulheres sobre a realização do exame citológico cérvicouterino. Revista de enfermagem UFPE on line [Internet]. 2014 [acesso em: 06 set. 2017];8(1):90-7. Disponível em: https://periodicos.ufpe.br/revistas/revistaenfermagem/article/view/9610.

11. Silva SÉD, Vasconcelos EV, Santana ME, Lima VLA, Carvalho FL, Mar DF. Representações sociais de mulheres amazônidas sobre o exame papanicolau: implicações para a saúde da mulher. Esc Anna Nery [Internet]. 2008 [acesso em: 06 set. 2017];12(4):685-92. Disponível em: http://dx.doi.org/10.1590/S1414-81452008000400012.

12. Silva IF, Koifman RJ, Koifman S, Mattos IE. Natural history of precancerous cervical lesions: an exploratory study of a cohort of women from Rio de Janeiro - RJ, Brazil. Revista Brasileira de Cancerologia [Internet]. 2012 [acesso em: 06 set. 2017];58(3):369-78. Disponível em:

http://www.inca.gov.br/rbc/n_58/v03/pdf/06_artigo_natural_history_precancerous_cervical_lesions_exploratory_st udy_cohort_women_rio_de_janeiro_rj_brazil.pdf.

13. Gu C, Chen WT, Zhang Q, Chow KM, Wu J, Tao L et al. Exploring Chinese Women's Perception of Cervical Cancer Risk as It Impacts Screening Behavior: A Qualitative Study. Cancer Nurs [Internet]. 2017 [acesso em: 06 set.

2017];40(4):E17-25. Disponível em: http://dx.doi.org/10.1097/NCC.0000000000000400.

14. Mascarello KC, Zandonade E, Amorim MHC. Survival analysis of women with cervical cancer treated at a referral hospital for oncology in Espírito Santo State, Brazil, 2000-2005. Cad Saude Publica [Internet]. 2013 [acesso em: 06 set. 2017];29(4):823-31. Disponível em: http://dx.doi.org/10.1590/S0102-311X2013000400019.

15. Cruz LMB, Loureiro RP. A comunicação na abordagem preventiva do câncer do colo do útero: importância das influências histórico-culturais e da sexualidade feminina na adesão às campanhas. Saude Soc [Internet]. 2008 [acesso em: 06 set. 2017];17(2):120-31. Disponível em: http://dx.doi.org/10.1590/S0104-12902008000200012.

16. Vargens OMC, Silva CM, Silva GA, Girianelli VR. Diagnóstico de HPV: o processo de interação da mulher com seu parceiro. Rev Bras Enferm [Internet]. 2013 [acesso em: 06 set. 2017];66(3):327-32. Disponível em:

http://dx.doi.org/10.1590/S0034-71672013000300004.

17. Nascimento MV, Souza I, Deus MSM, Peron AP. O que sabem os adolescentes do ensino básico público sobre o HPV. Semina: Ciências Biológicas e da Saúde [Internet]. 2013 [acesso em: 06 set. 2017];34(2):229. Disponível em: http://dx.doi.org/10.5433/1679-0367.2013v34n2p229.

18. Queiroz, Alda Maria Alves; Cano, Maria Aparecida Tedeschi; Zaia, José Eduardo. O papiloma vírus humano (HPV) em mulheres atendidas pelo SUS na cidade de Patos de Minas - MG. Revista Brasileira de Análises Clínicas [Internet].

Rev. Eletr. Enf. [Internet]. 2017 [acesso em:_/_/_];19:a23. Disponível em: http://dx.doi.org/10.5216/ree.v19.41334. 
2007 [acesso em: 06 set. 2017];39(2):151-7. Disponível em: http://www.rbac.org.br/wp-

content/uploads/2016/08/RBAC Vol39 n2-Completa.pdf.

19. Mendonça VG, Guimarães MJB, Lima Filho JL, Mendonça CG, Martins DBG, Crovella S et al. Infecção cervical por papilomavírus humano: genotipagem viral e fatores de risco para lesão intraepitelial de alto grau e câncer de colo do útero. Rev Bras Ginecol Obstet [Internet]. 2010 [acesso em: 06 set. 2017];32(10):476-85. Disponível em:

http://dx.doi.org/10.1590/S0100-72032010001000002.

20. Ito MM, Vargas SM, Suzuki LE, Merlin JC. Dimensão da participação do Papilomavírus humano (HPV) na evolução do câncer cérvico-vaginal. Revista Brasileira de Análises Clínicas [Internet]. 2010 [acesso em: 06 set. 2017];42(2):1517. Disponível em: http://www.rbac.org.br/wp-content/uploads/2016/08/RBAC Vol42_n2-Completa.pdf.

21. Nascimento LC, Nery IS, Silva AO. Conhecimento cotidiano de mulheres sobre a prevenção do câncer de colo do útero. Revista Enfermagem UERJ [Internet]. 2012 [acesso em: 06 set. 2017];20(4):476-80. Disponível em:

http://www.facenf.uerj.br/v20n4/v20n4a11.pdf.

22. Silva SÉD, Vasconcelos EV, Santana ME, Rodrigues ILA, Mar DF, Carvalho FL. Esse tal Nicolau: representações sociais de mulheres sobre o exame preventivo do câncer cérvico-uterino. Rev Esc Enferm USP [Internet]. 2010 [acesso em: 06 set. 2017];44(3):554-60. Disponível em: http://dx.doi.org/10.1590/S0080-62342010000300002.

23. Jorge RJB, Diógenes MAR, Mendonça FAC, Sampaio LRL, Jorge Júnior R. Exame Papanicolaou: sentimentos relatados por profissionais de enfermagem ao se submeterem a esse exame. Cien Saude Colet [Internet]. 2011 [acesso em: 06 set. 2017];16(5):2443-51. Disponível em: http://dx.doi.org/10.1590/S1413-81232011000500013.

24. Lucena LT, Zãn DG, Crispim PTB, Ferrari JO. Fatores que influenciam a realização do exame preventivo do câncer cérvico-uterino em Porto Velho, Estado de Rondônia, Brasil. Rev Panamazonica Saude [Internet]. 2011 [acesso em: 06 set. 2017];2(2):45-50. Disponível em: http://dx.doi.org/10.5123/S2176-62232011000200007. 